\title{
The influence of ternary alloying element in iron aluminides on coefficient of thermal expansion
}

\author{
M. Švec ${ }^{1 *}$, P. Kejzlar ${ }^{2}$ \\ ${ }^{1}$ Technical University of Liberec, Faculty of Engineering, Department of Material Science, \\ Studentská 1402/2, 46117 Liberec, Czech Republic \\ ${ }^{2}$ Institute for Nanomaterials, Advanced Technologies and Innovation, Technical University of Liberec, \\ Studentská 1402/2, 46117 Liberec, Czech Republic
}

Received 17 July 2015, received in revised form 13 October 2015, accepted 5 November 2015

\begin{abstract}
The iron aluminides appear as suitable materials with many advantages for use in high-temperature applications. However, a sharp drop in their strength above $600{ }^{\circ} \mathrm{C}$ and limited ductility at room temperature are the major obstacles to their mass expansion. There are several possibilities how to improve these negative properties. One possibility is alloying of binary alloys by another element.

The main aim of present work is to evaluate the effect of different alloying elements on the coefficient of thermal expansion with respect to phase composition and structure. Generally, the high mechanical temperature properties are affected by alloy structure, and the same could be supposed for the coefficient of thermal expansion (CTE). In this paper, there were studied Fe-26Al-2X ( $X=\mathrm{Cr}, \mathrm{Si}, \mathrm{Ta}, \mathrm{Zr})$ alloys. Structure and phase composition were evaluated by SEM, EDX, and EBSD. The CTE's were examined in a temperature range $460-1200^{\circ} \mathrm{C}$ using horizontal dilatometer.

Precipitates of ternary phases can beneficially affect the CTE's values. The lowest and most stable CTE was observed for iron aluminide with Ta-addition.
\end{abstract}

K e y w ord s: iron aluminides, $\mathrm{Fe}_{3} \mathrm{Al}$, structure, coefficient of thermal expansion (CTE)

\section{Introduction}

The iron aluminides seem to be very perspective materials for structural applications. They are characterized by a wide range of benefits, for example by good strength up to $600^{\circ} \mathrm{C}$, excellent corrosion resistance, lower density than stainless steel and low price of raw materials. However, some negative properties, for example, a sharp drop in strength above $600^{\circ} \mathrm{C}$, are the major obstacles to their mass expansion [14]. Industrial applications require better mechanical properties at high temperature than can be achieved by binary Fe-Al alloy. This is the reason for alloying of iron aluminides by different alloying elements. Naturally, it can be expected that coefficient of thermal expansion is also affected by the addition of these elements.

Four basic possibilities were described how to strengthen iron aluminides [5-7].
First - by solid solution hardening. This option is possible in systems with sufficient solubility of alloying element in the matrix. The alloying element is dissolved into the matrix, and thus it strengthens. Suitable alloying element for this type of reinforcement is, for example, chromium or silicon. Chromium is dissolved in the $\mathrm{Fe}-\mathrm{Al}$ matrix up to 50 at.\%, and no other secondary phases can form [6].

Second - by alloy ordering. This option is based on $\mathrm{D0}_{3}$ structure stabilization at high temperature. Through the addition of suitable alloying element (in this case, for example, titanium), it is achieved that the transition temperature $T_{\mathrm{C}}$ (transition from $\mathrm{D}_{3}$ to B2 lattice) is shifted to higher values than the binary diagram $\mathrm{Fe}-\mathrm{Al}$ indicates. Thereby the existence of $\mathrm{DO}_{3}$ structure is extended [6].

Third - by incoherent precipitates. Solid solubility of the most of alloying elements in binary Fe-Al system is limited. The higher addition of alloying element

*Corresponding author: e-mail address: martin.svec@tul.cz 
than is its solubility limit in the alloy leads to the formation of incoherent precipitates. The precipitates are frequently formed by intermetallic phases, carbides or borides, and they also contribute to hardening of iron aluminides [7]. An example of an element that forms incoherent precipitates can be zirconium.

The last one and the most reinforcing effect is hardening by coherent precipitates. Coherent precipitates are formed due to miscibility gap. It is a region of the phase diagram in which two phases with essentially the same structure are not miscible or soluble. Miscibility gap allows the formation of coherent precipitates with strong reinforcement effect. The coherent precipitates can be observed for example in the systems Fe-Al-V, Fe-Al-Ni, Fe-Al-Ti or Fe-Al-Ta [6-8]. Iron aluminides appear as ideal materials for high-temperature applications (and possible substitute for P91, P92 type stainless steels) due to their excellent resistance to high-temperature oxidation and corrosion. Until now, almost all publications dealing with $\mathrm{Fe}-\mathrm{Al}$ alloys are closely related to the study and description of the structure, high-temperature mechanical properties (strength, creep) and corrosion behaviour. The measurement of coefficient of thermal expansion is important because CTE together with the high-temperature strength limits the use of these materials [9]. The knowledge of their behaviour at high temperatures is essential for the use of iron aluminides in high-temperature applications.

The dimensional changes are measured by a mechanical digital indicator; temperature is measured by a thermocouple. The true or medium coefficient of linear thermal expansion (CTE) can be determined from the recorded data [9-11]. The medium coefficient $\alpha_{\text {med }}$ is determined from the Eq. (1):

$$
\alpha_{\text {med }}=\frac{l_{\mathrm{T}}-l_{0}}{T-T_{0}} \cdot \frac{1}{l_{0}},
$$

where $l_{\mathrm{T}}$ is the length of the sample at the given temperature, $l_{0}$ is the length of the sample at the room temperature $\left(20^{\circ} \mathrm{C}\right), T$ is given applied temperature and $T_{0}$ is room temperature $\left(20^{\circ} \mathrm{C}\right)$

The intention to use iron aluminides in high-tech applications as e.g. steam turbine blade makes the knowledge of CTE indispensable.

\section{Materials and experimental methods}

The investigated alloys were $\mathrm{Fe}_{3} \mathrm{Al}$-type iron aluminides with 26 at.\% of $\mathrm{Al}$ and addition of 2 at.\% of different elements (chromium, silicon, tantalum, and zirconium). The samples were prepared by induction vacuum melting.

For the study of their microstructure, they were oxide-polished by suspension OP-S. The structure

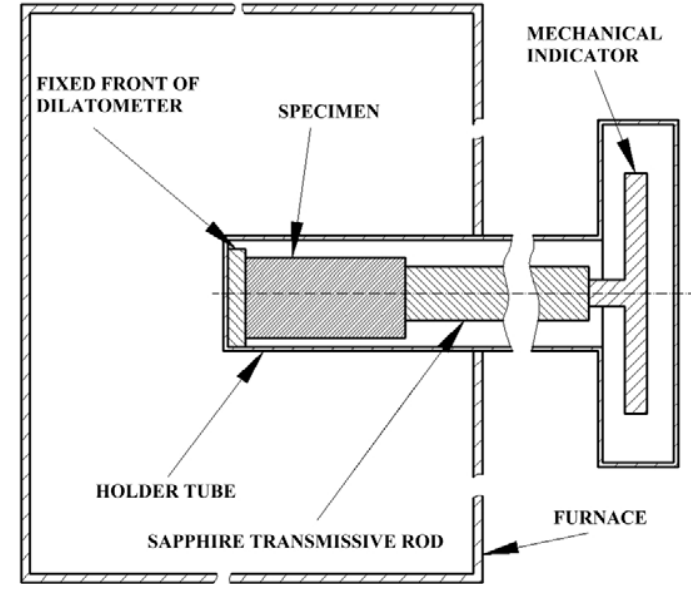

Fig. 1. A scheme of the apparatus used for measurement of dilatation cycle.

Table 1. The applied temperature cycle for dilatation measurement

\begin{tabular}{ll}
\hline Step & Conditions \\
\hline 1 & $25-250{ }^{\circ} \mathrm{C} \rightarrow$ heating rate $7^{\circ} \mathrm{C} \min ^{-1}$ \\
2 & $250-1200^{\circ} \mathrm{C} \rightarrow$ heating rate $4^{\circ} \mathrm{C} \min ^{-1}$ \\
3 & $1200{ }^{\circ} \mathrm{C} \rightarrow$ delay at temperature 15 min \\
4 & $1200-700^{\circ} \mathrm{C} \rightarrow$ cooling rate $4^{\circ} \mathrm{C} \min ^{-1}$ \\
5 & $700-25^{\circ} \mathrm{C} \rightarrow$ cooled at a rate less than $4^{\circ} \mathrm{C} \mathrm{min}$ min $^{-1}$ \\
\hline
\end{tabular}

was observed by the light optical microscope Nikon Epiphot 200 (with the use of differential interference contrast - DIC). The microstructural details and the phase composition were studied by the scanning electron microscope (SEM) Zeiss ULTRA Plus equipped with Oxford detector for energy-dispersive analysis (EDX). Presented phases were confirmed using EBSD analysis (Oxford NodlysNano) on SEM Zeiss ULTRA Plus.

Thermal expansion was measured using horizontal dilatometer. A scheme of the measuring apparatus is in Fig. 1. During the measurement, the sample was placed into a holder of dilatometer and the whole system was inserted into the furnace. The holder and transmissive rod were made from sapphire. Applied temperature cycle for dilatation measurement is given in Table 1 . The heating cycle lasts about $4.5 \mathrm{~h}$. Repeatedly reached deviation was from 5 to $7 \%$ in the temperature range $25-600{ }^{\circ} \mathrm{C}, 2-4 \%$ in range $600-$ $1000^{\circ} \mathrm{C}$ and $0.5-1 \%$ in range $1000-1200{ }^{\circ} \mathrm{C}$. The first cycle (without sample) serves for calibration of the system. An example of recorded dilatation curves is given in Fig. 2. Insignificant hysteresis between heating and cooling curves (Fig. 2) suggests sufficient time for phase transformation. The CTE values were calculated from heating curves according to Eq. (1). Slopes 


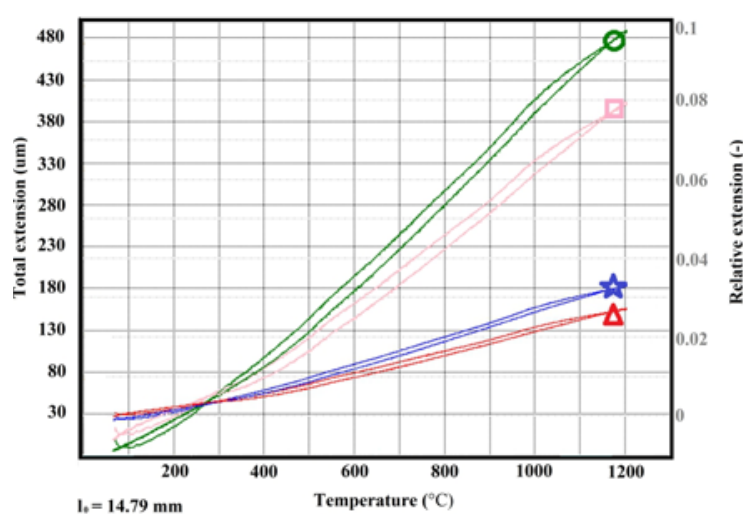

Fig. 2. An example of expansion curves: green curve (circle) - the total extension of the system (sample + sapphire adapter rod); pink curve (square) - the absolute extension of sample; blue curve (star) - the relative extension of the system; red curve (triangle) - the relative extension of the sample.

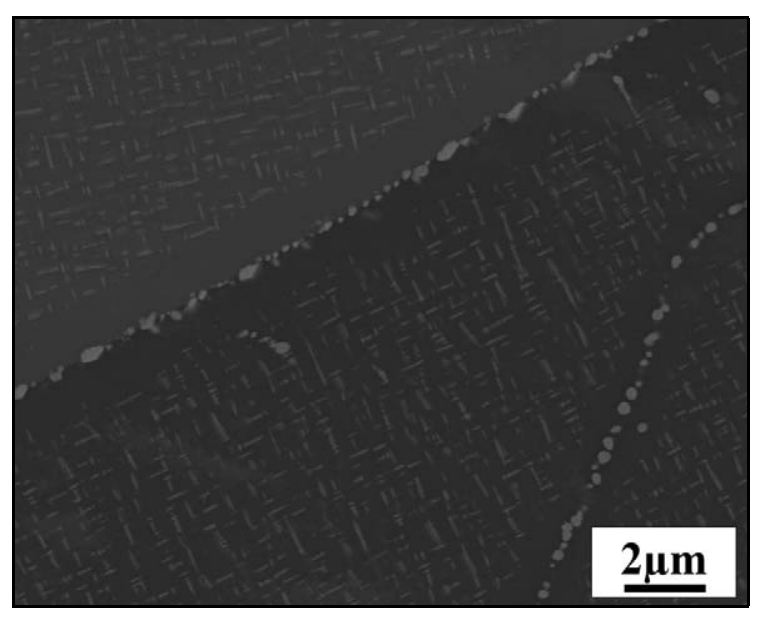

Fig. 3. The structure of Fe-Al-Ta alloy with the particles of Laves phase on grain boundaries and with the precipitates of Heusler phase inside the grains (initial state).

of the CTE curves were calculated using a linear regression in the temperature ranges corresponding to the occurrence of investigated phases.

\section{Results and discussion}

\subsection{Microstructure and phase identification}

Almost all high-temperature properties are affected by alloy microstructure. Therefore, the microstructure knowledge is important for the explanation of alloy behaviour and properties at high temperatures.

There occurs the combination of two hardening mechanisms in the Fe-Al-Ta system - strengthening

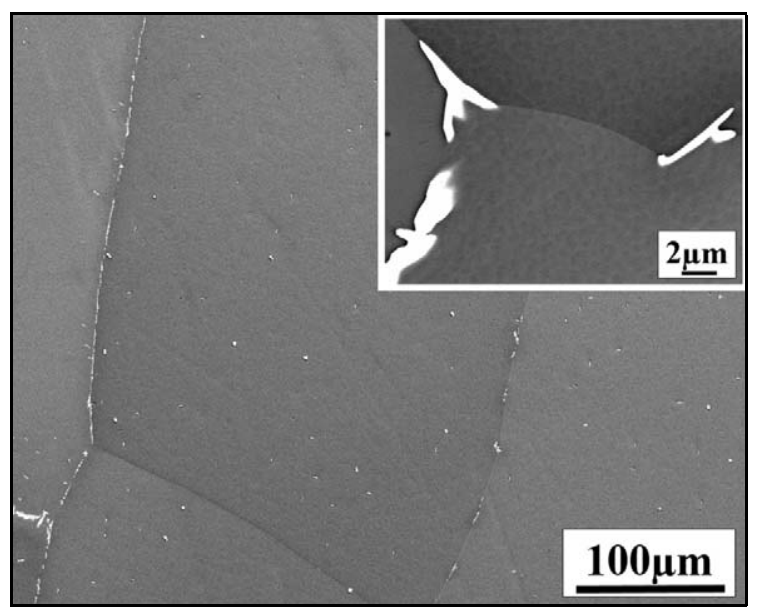

Fig. 4. The structure of Fe-Al-Ta alloy after dilatation cycle. Only Laves phase is presented in the structure - on grain boundaries and also inside the grains, no precipitates of Heusler phase were observed.

by incoherent precipitates and by coherent precipitates. The structure of material Fe-Al-Ta is shown in Fig. 3. The coarser particles on the grain boundaries were identified by EDX and EBSD as incoherent C14 Laves phase with chemical composition Fe-10.1Al-24.5Ta (at.\%). Inside the grains, there were observed very fine and densely distributed particles of coherent Heusler phase with a thickness about 10 $\mathrm{nm}$, and, therefore, they are very suitable for blocking of dislocations movement, and they can improve the creep resistance $[12,13]$. The precipitates of Heusler phase are metastable in the system Fe-Al-Ta. In equilibrium, the Laves phase is formed. However, the nucleation of Laves phase is a kinetic problem, so the metastable Heusler phase is formed first. The nucleation problem of the Laves phase is visible in Fig. 3. The Laves phase particles start to nucleate at the most appropriate energy location - on grain boundaries. In Fig. 3 there is also seen a denuded zone without precipitates, no precipitates of Heusler or Laves phase were observed in this area. It is caused by the formation of stable Laves phase precipitates on grain boundaries. Tantalum from the matrix goes into the Laves phase particles. Therefore, the stripe along the line of precipitates is deprived about tantalum. The amount of tantalum around Laves phase particles falls below the solubility limit in Fe-Al-Ta system, the remaining tantalum can be dissolved into the matrix and the denuded stripe is occurred. In [13] Heusler phase was observed after annealing at $700^{\circ} \mathrm{C}$. However, only Laves phase particles were observed after annealing at $800^{\circ} \mathrm{C}$. In agreement with TTT diagram [13] and phase diagrams [14], no precipitates of Heusler phase were observed in the structure after dilatation cycle (see a cut in Fig. 4), only Laves phase particles were observed. Laves phase particles were distributed on 


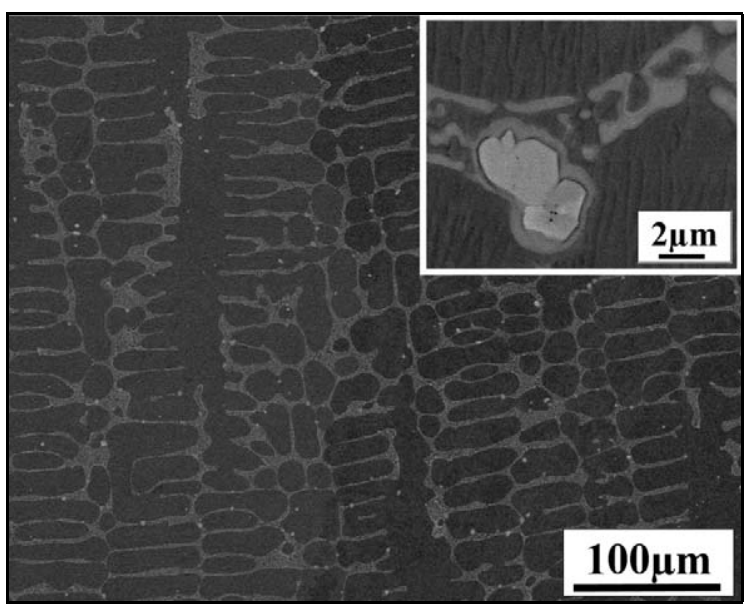

Fig. 5. The as-cast structure of Fe-Al-Zr alloy (initial state). $\lambda_{1}$ Laves phase creates a fine lamellar eutectic with $\mathrm{Fe}_{3} \mathrm{Al}$ phase.

grain boundaries and also inside the grains, what is obvious in Fig. 4, and they can improve the mechanical properties at temperatures above $800^{\circ} \mathrm{C}$, which is limiting temperature for the existence of Heusler phase $[12,13]$.

The solid solubility of $\mathrm{Zr}$ in $\mathrm{Fe}-\mathrm{Al}$ matrix does not exceed 0.1 at. $\%$ in a whole temperature range, which is why even a minor addition of $\mathrm{Zr}$ leads to precipitation of $\lambda_{1}$ and/or $\tau_{1}$ phase according to Al-Fe$\mathrm{Zr}$ ternary diagram [15]. In the Fe-Al-Zr alloy in an as-cast state, there was observed a fine lamellar eutectic composed of $\lambda_{1}$ Laves phase and $\mathrm{Fe}_{3} \mathrm{Al}$ in $\mathrm{Fe}_{3} \mathrm{Al}$ matrix (see Fig. 5). A total volume fraction of the eutectic is approximately $20 \%$. Small bright particles appearing in the structure were identified as $\mathrm{ZrC}$ and $\mathrm{Zr}_{2} \mathrm{CS}$; their amount is $<0.5 \%$. The presence of $\mathrm{ZrC}$ and $\mathrm{Zr}_{2} \mathrm{CS}$ could be explained due to a high affinity of $\mathrm{Zr}$ to carbon and sulphur, which were presented as impurities in a raw material. The structure after dilatation cycle is in Fig. 6. The fine lamellar eutectic was replaced by coarser particles of Laves phase. In the detailed cut, there is visible, that $\mathrm{ZrC}$ particles act as a nucleus for precipitation of coarse Laves phase particles.

In the $\mathrm{Fe}-\mathrm{Al}-\mathrm{Cr}$ system there exists a wide area of solid chromium solubility in the iron aluminides matrix (see phase diagram in [16]). Therefore, no precipitates were observed in the structure, what is obvious from Fig. 7. Even after the dilatation cycle no changes in the structure were observed. The same hardening mechanism applies for Fe-Al-Si system. It is evident from phase diagram [17] that solid solubility of silicon is higher than 2 at.\% (the investigated material has this composition). Therefore, again there were no precipitates in the structure - see Fig. 8. Also after the dilatation cycle no changes in the structure were observed. According to the Hägg's ratio the atoms of

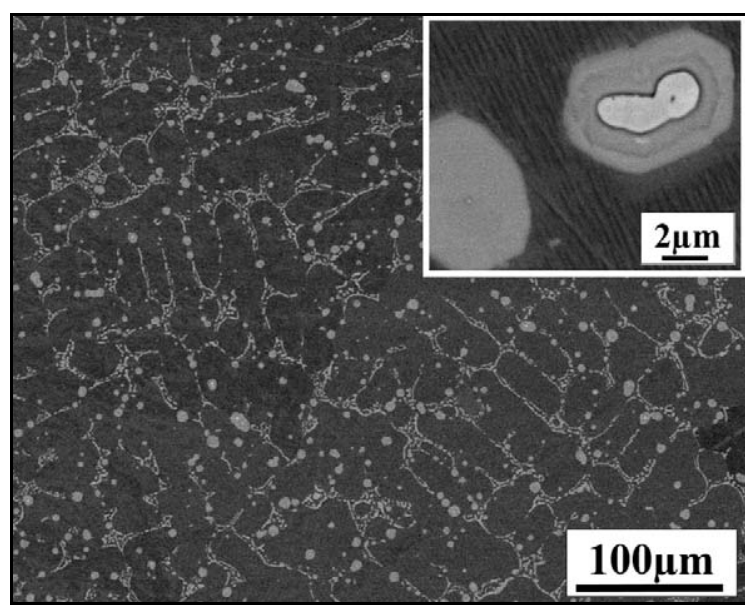

Fig. 6. The structure of Fe-Al-Zr alloy after dilatation cycle. In the $\mathrm{Fe}_{3} \mathrm{Al}$ matrix, there are coarser particles of Laves phase (sometimes with $\mathrm{ZrC}$ core).

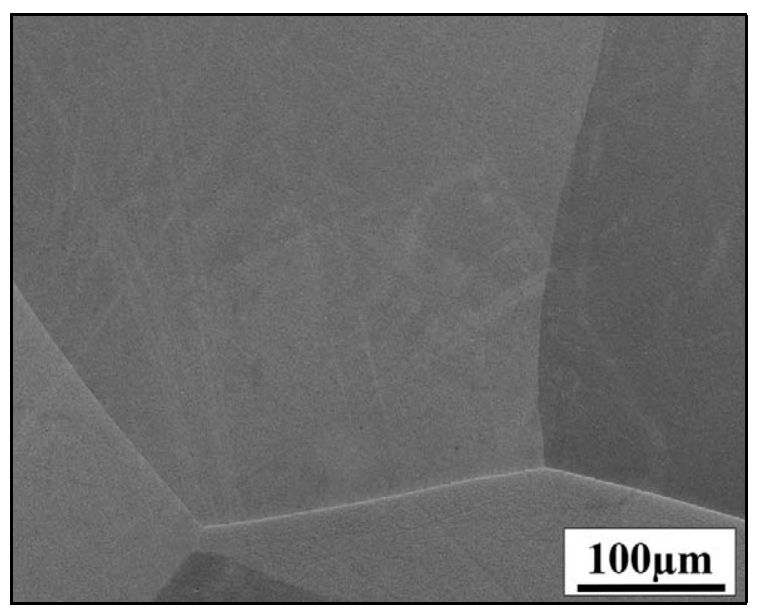

Fig. 7. The structure of Fe-Al-Cr alloy in initial state - no particles were observed.

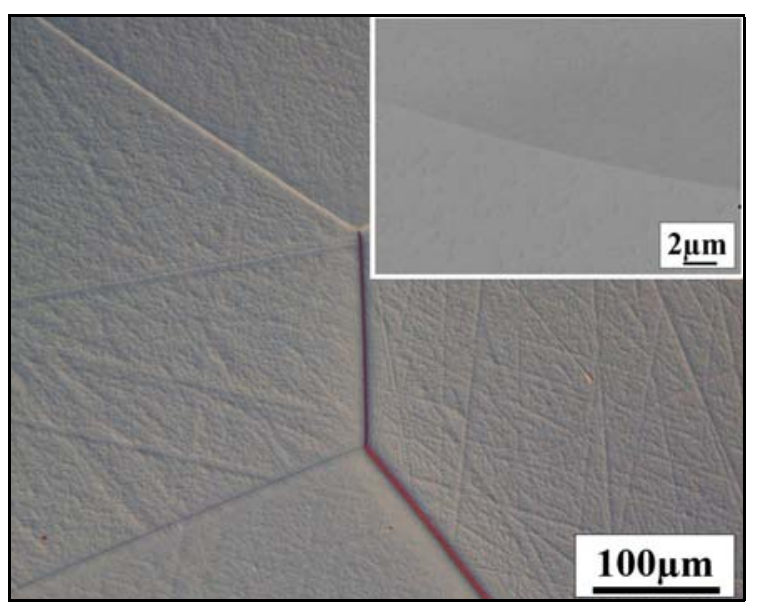

Fig. 8. The structure of Fe-Al-Si alloy in initial state - no particles were observed. 
Table 2. The values of the slopes of CTE curves and phase transformation temperatures

\begin{tabular}{|c|c|c|c|c|c|c|}
\hline \multirow[b]{2}{*}{ System } & \multicolumn{6}{|c|}{ Structure } \\
\hline & $\mathrm{DO}_{3}$ & $\begin{array}{c}\mathrm{D}_{3}+ \\
\text { precipitates* }\end{array}$ & B2 & $\begin{array}{c}\mathrm{B} 2+ \\
\text { precipitates* }\end{array}$ & $\alpha \mathrm{Fe}$ & $\begin{array}{c}\alpha \mathrm{Fe}+ \\
\text { precipitates* }\end{array}$ \\
\hline Fe-Al-Ta & - & $\begin{array}{c}\text { SoC: } 0.0111 \\
T_{\mathrm{r}} \text { : up to } 580^{\circ} \mathrm{C} \\
{ }^{*} \text { Heusler }+ \text { Laves }\end{array}$ & - & $\begin{array}{c}\text { SoC: } 0.0076 \\
T_{\mathrm{r}}: 580-760^{\circ} \mathrm{C} \\
{ }^{*} \text { Heusler }+ \text { Laves } \\
\text { SoC: } 0.0016 \\
T_{\mathrm{r}}: 760-920^{\circ} \mathrm{C} \\
{ }^{*} \text { Laves phase }\end{array}$ & 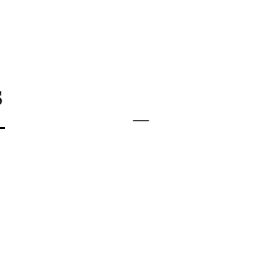 & $\begin{array}{l}\text { SoC: }-0.0019 \\
T_{\mathrm{r}}: \text { above } 920^{\circ} \mathrm{C} \\
\quad \text { *Laves phase }\end{array}$ \\
\hline $\mathrm{Fe}-\mathrm{Al}-\mathrm{Zr}$ & - & $\begin{array}{l}\text { SoC: } 0.0197 \\
\text { Tr: up to } 560^{\circ} \mathrm{C} \\
\text { *Laves phase }\end{array}$ & - & $\begin{array}{l}\text { SoC: } 0.0059 \\
T_{\mathrm{r}}: 560-780^{\circ} \mathrm{C} \\
{ }^{*} \text { Laves phase }\end{array}$ & - & $\begin{array}{l}\text { SoC: }-0.0029 \\
T_{\mathrm{r}}: \text { above } 780^{\circ} \mathrm{C} \\
\quad \text { *Laves phase }\end{array}$ \\
\hline Fe-Al-Cr & $\begin{array}{c}\text { SoC: } 0.0166 \\
T_{\mathrm{r}}: \text { up to } 600^{\circ} \mathrm{C}\end{array}$ & - & $\begin{array}{c}\text { SoC: } 0.0042 \\
T_{\mathrm{r}}: 600-960^{\circ} \mathrm{C}\end{array}$ & - & $\begin{array}{c}\text { SoC: }-0.0019 \\
T_{\mathrm{r}}: \text { above } 960^{\circ} \mathrm{C}\end{array}$ & - \\
\hline Fe-Al-Si & $\begin{array}{c}\text { SoC: } 0.0093 \\
T_{\mathrm{r}} \text { : up to } 680^{\circ} \mathrm{C}\end{array}$ & - & $\begin{array}{c}\text { SoC: } 0.0055 \\
T_{\mathrm{r}}: 680-1080^{\circ} \mathrm{C}\end{array}$ & - & $\begin{array}{c}\text { SoC: }-0.0075 \\
T_{\mathrm{r}}: \text { above } 1080^{\circ} \mathrm{C}\end{array}$ & - \\
\hline
\end{tabular}

Note: SoC is the slope of the CTE curve, and $T_{\mathrm{r}}$ is temperature range.

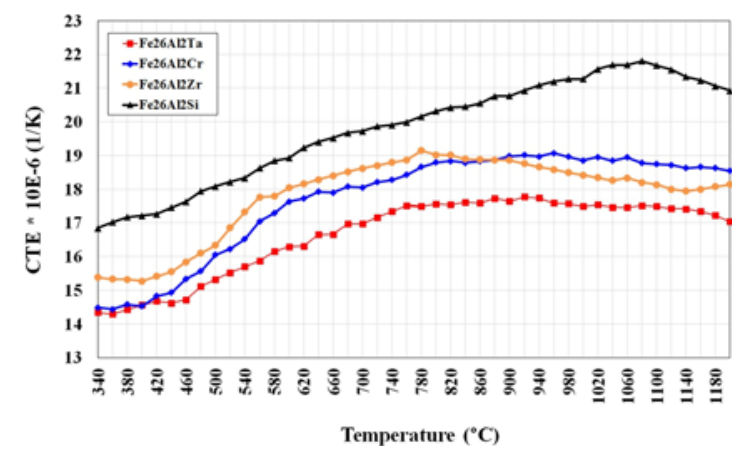

Fig. 9. The chart of CTE curves for the investigated alloys.

alloying element have to have mutual size ratio lower than 0.59 (for interstitial elements) or in the range of 0.9-1.1 (for substitutional elements) to be solid soluble. In the case of $\mathrm{Fe}-\mathrm{Al}-\mathrm{Cr}$ alloy, there is the atom size ratio for $\mathrm{Cr} / \mathrm{Fe}=1.06$ and $\mathrm{Cr} / \mathrm{Al}=1.41$. For $\mathrm{Fe}-\mathrm{Al}-\mathrm{Si}$ alloy the atom size ratio is $\mathrm{Si} / \mathrm{Fe}=0.71$ and $\mathrm{Si} / \mathrm{Al}=0.94$. With respect to the Hägg's ratio, it can be supposed that in the system Fe-Al-Cr there will be replaced iron atoms by chromium while in the case of Fe-Al-Si alloy the silicon will replace aluminium.

\subsection{Coefficient of thermal expansion}

Figure 9 shows the chart of CTE curves for the investigated alloys. In Table 2 there are summarized the slopes of CTE curves in different phases for all investigated alloys.
For the binary Fe26Al alloy phase, transformation temperatures were calculated from the phase diagram [1]. The binary alloy undergoes two phase transformations $\left(\mathrm{D0}_{3} \leftrightarrow \mathrm{B} 2 \leftrightarrow \alpha \mathrm{Fe}\right.$ ) at approximately $550^{\circ} \mathrm{C}$ and $790^{\circ} \mathrm{C}$.

From the chart (Fig. 9) is seen that the CTE values for Fe-Al-Ta are the lowest in a whole range of measured temperatures. The CTE values are also relatively stable from medium to high temperatures (the values fluctuate between $14.5 \times 10^{-6}$ and $18 \times 10^{-6}$ $\mathrm{K}^{-1}$ ). The first change in the slope of CTE curve is seen at $580^{\circ} \mathrm{C}$ when the structure is changed from $\mathrm{D}_{3}$ to B2. The slope change is relatively minimal due to the existence of coherent Heusler phase and incoherent Laves phase in the structure. Heusler phase disappears at approximately $760^{\circ} \mathrm{C}$ - the second slope change in the chart. In the temperature range $760-920^{\circ} \mathrm{C}$ there exists B2 matrix with Laves phase precipitates. The final slope change occurs at $920^{\circ} \mathrm{C}$ when the ordered B2 transforms to disordered $\alpha \mathrm{Fe}$. The Laves phase particles remain in the structure.

The initial structure of Fe-Al-Zr is composed of a mixture of $\mathrm{DO}_{3}+$ Laves phase. The presence of $\mathrm{ZrC}$ precipitates can be neglected, because their volume fraction is too low to affect the CTE. The CTE curve corresponding to $\mathrm{DO}_{3}+$ Laves phase structure rises the most steeply of all investigated alloys. The first change in the CTE curve slope is evident at $560{ }^{\circ} \mathrm{C}$ where $\mathrm{D0}_{3}$ lattice transforms to B2. CTE further grows linearly up to $780^{\circ} \mathrm{C}$ (transformation from ordered B2 to disordered $\alpha \mathrm{Fe}$ ). Above $780^{\circ} \mathrm{C}$, the CTE values decrease with the temperature. 
The CTE curve of Fe-Al-Cr alloy grows in the temperature interval from 460 to $960^{\circ} \mathrm{C}$. The maximum of CTE value is reached at $960^{\circ} \mathrm{C}$. The first decrease in the slope of the CTE line is evident at a temperature of $600{ }^{\circ} \mathrm{C}$ where occurs a phase transformation from $\mathrm{D0}_{3}$ to B2. A decrease of CTE values with increasing temperature starts at $960^{\circ} \mathrm{C}$. The decrease is related to a transformation from the ordered B2 structure to disordered $\alpha \mathrm{Fe}$.

In the temperature range from 460 to $1080{ }^{\circ} \mathrm{C}$, the CTE of Fe-Al-Si alloy grows almost linearly with the temperature. A small decrease in the slope of the CTE curve could be observed around $680^{\circ} \mathrm{C}$ approximately when the phase transformation from $\mathrm{D}_{3}$ to $\mathrm{B} 2$ occurs. The CTE values decrease above $1080^{\circ} \mathrm{C}$, what could be explained by a transformation from $\mathrm{B} 2$ to the disordered $\alpha$ Fe lattice. The Fe-Al-Si alloy shows the highest CTE values in the whole temperature range for all investigated samples. In the Fe-Al-Si, there applies the same reinforcing mechanism as in the $\mathrm{Fe}-\mathrm{Al}-\mathrm{Cr}$ system. However, the coefficient of thermal expansion is significantly higher for Fe-Al-Si. This is probably caused by the fact that in the Fe-Al-Si system silicon replaces aluminium, however in the Fe-Al-Cr system chromium substitutes iron. With respect to mechanical properties, it is more beneficial to replace iron than aluminium in the case of Fe-Al- $X$ ternary system.

\subsection{Summary}

Besides the temperature, CTE values are strongly affected by the structural lattice. The steepest increase in CTE curve shows the $\mathrm{D}_{3}$ lattice. The milder increase of CTE with the temperature was observed in the case of the B2 lattice. On the other hand, the CTEs of $\alpha \mathrm{Fe}$ decrease with the growing temperature.

Stable and low values of CTE are required for the use at high temperatures. Due to this fact, B2 and $\alpha \mathrm{Fe}$ lattices are more beneficial than $\mathrm{D}_{3}$. For keeping the lowest possible CTE values, it is desired that $\mathrm{D0}_{3} \leftrightarrow \mathrm{B} 2$ and $\mathrm{B} 2 \leftrightarrow \alpha \mathrm{Fe}$ transformations took place at lowest temperatures. It is necessary to keep in mind that Fe-Al-type alloys are suitable for machine parts up to $800^{\circ} \mathrm{C}$ with respect to their high-temperature mechanical properties.

It is obvious (see Table 2) that transformation temperatures are affected by the alloying elements. While the addition of $\mathrm{Cr}$, $\mathrm{Ta}$ and $\mathrm{Zr}$ does not affect the $\mathrm{D0}_{3} \leftrightarrow \mathrm{B} 2$ phase transformation temperature significantly, the addition of Si shifted the transition temperature from 550 to $680^{\circ} \mathrm{C}$. Except $\mathrm{Zr}$ addition similar phase transformation temperature shift due to the addition of ternary element was observed in the $\mathrm{B} 2 \leftrightarrow \alpha \mathrm{Fe}$ transformation.

The effect of ternary element addition on the slope of CTE curves is also obvious from Table 2. The most stable CTE values were observed in the case of Ta- and Cr-alloyed samples. The addition of $\mathrm{Zr}$ caused the steepest grow of CTE at lower temperatures, above $560^{\circ} \mathrm{C}$ the $\mathrm{SoC}$ (slope of the CTE curve) values are comparable to the other alloys. Si-alloyed sample shows the steepest decrease of CTE in the $\alpha \mathrm{Fe}$ area.

With respect to CTE, the addition of $\mathrm{Ta}$ is the most beneficial for the required application temperatures for Fe-Al alloys (approximately up to $900^{\circ} \mathrm{C}$ ).

Results obtained by Cr- and Zr-doped alloys were similar to each other ( $\mathrm{Cr}$ seems to be better at temperatures below $860^{\circ} \mathrm{C}$, above $860^{\circ} \mathrm{C} \mathrm{Zr}$ should be preferred).

The addition of Si led to an increase of CTE in the whole tested temperature range.

Other studies in Fe-26Al-2X systems performed by DTA show well comparable results of transition temperature values to the results obtained from CTE measurements. E.g., in [18] there were measured $\mathrm{D}_{3} \leftrightarrow \mathrm{B} 2$ transition temperatures $\left(T_{\mathrm{C}}\right)$ by DTA. According to [18], $T_{\mathrm{C}} \mathrm{D0}_{3} \leftrightarrow \mathrm{B} 2$ for Fe-26Al-2Ta alloy (in at.\%) is approximately $580^{\circ} \mathrm{C}$, for $\mathrm{Fe}-26 \mathrm{Al}-2 \mathrm{Zr}$ (in at.\%) is $550{ }^{\circ} \mathrm{C}$ and for $\mathrm{Fe}-26 \mathrm{Al}-2 \mathrm{Cr}$ (in at.\%) is $610^{\circ} \mathrm{C}$ (for comparison with present CTE data see Table 2).

\section{Conclusions}

Obtained CTE values are essential for construction engineers in designing structural parts for hightemperature application. Also, the data obtained from CTE curves can be used for explanation of high-temperature deformation behaviour (relation between high-temperature strength and phase transformation) of Fe-Al- $X$ alloys.

- The lowest CTE was measured for material Fe-Al-Ta. Low and relatively stable CTE is very suitable for the materials used in structural applications. The most stable CTE values were observed in the case of Ta- and Cr-alloyed samples. It is obvious that tantalum assign to similar positive influence on CTE values stability as chromium (that is considered as a strategic element), the replacement of chromium by tantalum should be beneficial. In addition, it could be reached saving of alloying element (usual addition of tantalum in iron aluminides is $<2$ at.\%, while chromium 5-10 at. $\%$.

- Precipitates formed due to ternary addition can beneficially affect the values of CTE similarly as high-temperature mechanical strength.

- The present study can be further extended by:

- the effect of other ternary alloying elements;

- the effect of different $\mathrm{Al}$ concentration with fixed ternary element concentration;

- the effect of different ternary element concentration with constant $\mathrm{Al}$ content. 


\section{Acknowledgements}

The results of this project LO1201 were obtained with co-funding from the Ministry of Education, Youth and Sports as part of targeted support from the programme "Národní program udržitelnosti I".

\section{References}

[1] Mc Kamey, C. G.: Physical Metallurgy and Processing of Intermetallic Compounds. Eds.: Stoloff, N. S., Sikka, V. K. New York, Springer 1996. doi:10.1007/978-1-4613-1215-4_9

[2] Stoloff, N. S.: Mater. Sci. Eng. A, 258, 1998, p. 1. doi:10.1016/S0921-5093(98)00909-5

[3] Stoloff, N. S., Liu, C. T.: Microstructure and Properties of Materials. Iron Aluminides. Volume 2. Singapore, Word Scientific Publishing Co. Ptc. Ltd. 2000.

[4] Deevi, S. C., Sikka, V. K.: Intermetallics, 4, 1996, p. 357. doi:10.1016/0966-9795(95)00056-9

[5] Morris, D. G.: Intermetallics, 6, 1998, p. 753. doi:10.1016/S0966-9795(98)00028-4

[6] Palm, M.: Intermetallics, 13, 2005, p. 1286. $\underline{\text { doi:10.1016/j.intermet.2004.10.015 }}$
[7] Palm, M., Schneider, A., Stein, F., Sauthoff, G.: Mater. Res. Soc. Symp. Proc., 842, 2005, S1.7. doi:10.1557/PROC-842-S1.7

[8] Risanti, D. D., Sauthoff, G.: Intermetallics, 13, 2005, p. 1313. doi:10.1016/j.intermet.2004.12.029

[9] Švec, M., Hanus, P., Vodičková, V.: Manufacturing Technology, 13, 2013, p. 399.

[10] Porter, W. D., Maziasz, P. J.: Scripta Metall. Mater., 29, 1993, p. 1043. doi:10.1016/0956-716X(93)90175-R

[11] Kanagaraj, S., Pattanayak, S.: Cryogenics, 43, 2003, p. 399. doi:10.1016/S0011-2275(03)00096-1

[12] Hanus, P., Bartsch, E., Palm, M., Krein, R., Bauer-Partenheimer, K., Janschek, P.: Intermetallics, 18, 2010, p. 1379. doi:10.1016/j.intermet.2009.12.035

[13] Risanti, D. D., Sauthoff, G.: Intermetallics, 19, 2011, p. 1727. doi:10.1016/j.intermet.2011.07.008

[14] Raghavan, V.: J. Phase Equilib. Diff., 34, 2013, p. 328. doi:10.1007/s11669-013-0239-9

[15] Raghavan, V.: J. Phase Equilib. Diff., 31, 2010, p. 459. doi:10.1007/s11669-010-9746-0

[16] Raghavan, V.: J. Phase Equilib., 24, 2003, p. 257. doi:10.1361/105497103770330587

[17] Ghosh, G.: Aluminium-Iron-Silicon. In: Landolt-Börnstein Database. New Series IV/11 A2.

[18] Anthony, L., Fultz, B.: Acta Metall. Mater., 43, 1995, p. 3885. doi:10.1016/0956-7151(95)90171-X 